\title{
Estrogen Activity Inhibition
}

National Cancer Institute

\section{Source}

National Cancer Institute. Estrogen Activity Inhibition. NCI Thesaurus. Code C41476.

Estrogen Activity Inhibition involves interference with, such as receptor binding, or restraint of the biological function of biochemical substances (estrogens) secreted by the ovaries that have a specific regulatory effect on the activity of cells involved in development and maintenance of secondary female sex characteristics and control of the cyclical changes in the reproductive cycle, as well as pregnancy maintenance and an anabolic effect on protein metabolism and water retention. 